УДК 336.227.2.025

DOI https://doi.org/10.17308/vsu.proc.law.2020.3/2985

\title{
СКВОЗНОЙ ПОДХОД В КОНТЕКСТЕ ФАКТИЧЕСКОГО ПРАВА НА ДОХОДЫ В РОССИЙСКОМ НАЛОГОВОМ ПРАВЕ*
}

\author{
А. В. Демин, А. В. Николаев \\ Юридический институт Сибирского фбедерального университета \\ (г. Красноярск) \\ Поступила в редакцию 8 января 2020 г.
}

\begin{abstract}
Аннотация: анализируется генезис сквозного подхода в контексте фбактического права на доходь в налоговол праве России. Сделан вывод о тол, что на текущий молент развитие сквозного налогообложения в контексте фбактического права на доходь в российскол налоговом праве привело $\kappa$ расширению его приленения на все виды трансграничных доходов, облагаельх у источника в РФ, но ряд проблем его применения остается не урегулированнылм.

Ключевые слова: налоговое право, договор об избежании двойного налогообложения, фбактическое право на доходы, сквозной подход.

Abstract: the authors analyze the genesis of the look-through approach in context of the beneficial ownership to incomes in Russian tax law. The conclusion that at the moment, the development of look-through approach in the context of the beneficial ownership to incomes in Russian tax law has led to the expansion of its application to all types of cross-border income taxed at a source in the Russian Federation, but a number of problems of its application remain unresolved. Key words: tax law, double tax treaty, beneficial ownership to incomes, lookthrough approach.
\end{abstract}

В Модельной конвенции ОЭСР в отношении налогов на доходы и капитал (далее - МК ОЭСР) сквозной подход в контексте бенефициарной собственности на пассивные доходы появился в 2003 г. в ходе реформы Комментариев к ст. 10-12. Тогда текст прежней редакции п. 12 Комментария к ст. 10 , п. 8 к ст. 11 и п. 4 к ст. 12 , содержавших «негативное определение» бенефициарного собственника дохода (путем перечисления лиц, которые 200 не могут считаться таковыми), был скорректирован и трансформирован в условие о сквозном подходе: с учетом других условий, налагаемых статьями о дивидендах, процентах и роялти соответственно, право на льготы и преимущества в государстве источника дохода не утрачивается, если посредник, например агент или номинальный владелец, находящийся в договаривающемся государстве или в третьем государстве, размещается между бенефициаром и плательщиком, но бенефициарный собственник является резидентом другого договаривающегося государства.

* Исследование выполнено при финансовой поддержке РФФИ в рамках научного проекта № 19-011-00012 «Доктрина "beneficial owner" (бенефициарного собственника дохода) в налоговом праве России и зарубежных стран».

(C) Демин А. В., Николаев А. В., 2020 


\section{Финансовое право. Налоговое право}

Реформа Комментариев к ст. 10-12 в 2011-2014 гг. оставила положение о сквозном подходе содержательно неизменным, но формулировка текста соответствующих Комментариев была изменена с учетом трудностей ситуации, когда прямой получатель дохода и бенефициарный собственник являются резидентами двух разных государств. С 2014 г. и по настоящее время формулировки п. 12.7 Комментария к ст. 10, п. 11 Комментария к ст. 11 и п. 4.6 Комментария к ст. 12 МК ОЭСР остаются неизменными и концепт бенефициарной собственности на доходы функционирует в одном ряду со сквозным подходом: предоставление налоговых льгот в государстве источника дохода возможно, если компания-посредник размещается между бенефициаром и плательщиком дохода, но бенефициарным собственником дохода является резидент одного из государств - участников соглашения об избежании двойного налогообложения (далее - СИДН).

В ходе имплементации концепта бенефициарной собственности на доходы в российское налоговое законодательство (п. 4 ст. 7 и ст. 312 НК РФ) было имплементировано и связанное с ним условие о сквозном подходе: если иностранное лицо, которому российским налоговым агентом перечислен доход, является резидентом государства, с которым у РФ имеется СИДН, но при этом оно не признается лицом, имеющим фактическое право на доходы (далее - лицо, имеющее ФПД), то такое лицо не вправе претендовать на налоговые льготы по СИДН. Доходы считаются выплаченными не ему, а лицу (лицам), имеющему (имеющим) фактическое право на выплачиваемые доходы. Последнее вправе претендовать на налоговые льготы по СИДН. Вместе с тем если налоговому агенту известно реальное лицо, имеющее ФПД, то режим налогообложения выплаченных доходов определяется налогово-правовым статусом последнего. Здесь возможны три варианта:

1) лицо, имеющее ФПД - налоговый резидент государства (территории), с которым у РФ не имеется СИДН. Налогообложение осуществляется без предоставления договорных льгот и преимуществ, т. е. в соответствии с общими нормами российского законодательства о налогах и сборах (подп. 3 п. 4 ст. 7 НК РФ). Налоговый агент удерживает налог по общим ставкам, предусмотренным частью второй НК РФ, а именно: $15 \%$ в отношении дивидендов и $20 \%$ в отношении процентов и роялти;

2) лицо, имеющее ФПД - налоговый резидент государства (территории), с которым у РФ имеется СИДН, предусматривающее льготный налоговый режим выплачиваемых доходов. Налогообложение осуществляется в соответствии с указанным СИДН (подп. 2 п. 4 ст. 7 НК РФ). В этом случае лицо, имеющее ФПД, может воспользоваться налоговыми льготами по СИДН, заключенным РФ с государством, резидентом которого оно является, даже в том случае, когда доход выплачен иному лицу (например, кондуитной компании);

3) лицо, имеющее ФПД - налоговый резидент РФ. По общему правилу налогообложение производится без удержания налога при условии информирования налогового органа ${ }^{1}$ по месту постановки на учет органи-

${ }^{1}$ В Письме ФНС России от 20 апреля 2015 г. № ГД-4-3/6713@ представлена временная форма сообщения о налогообложении доходов, выплаченных в адрес 


\section{Вестник ВГУ. Серия: Право}

зации - источника выплаты дохода (подп. 1 п. 4 ст. 7 НК РФ)². То есть у налогового агента не возникает обязанностей удерживать налог, поскольку в әтом случае лицо, имеющее ФПД, будучи налоговым резидентом РФ, должно самостоятельно исчислить и уплатить сумму налога по общим правилам НК РФ. Исключение составляют выплаты пассивных доходов бизическим лицал ${ }^{3}$, а также - дивидендов ${ }^{4}$, когда налоги по общему правилу удерживаются российскими налоговыми агентами.

Как видим, налоговые последствия применения сквозного подхода зависят от того, является ли бенефициарный собственник полученного дохода российским налоговым резидентом или нет, а в последнем случае заключено ли Россией СИДН со страной резидентства лица, имеющего ФДП.

Возможно ли применение сквозного подхода к лицу, имеющему ФПД, если в корпоративной структуре группы (в цепочке вовлеченных посредников) присутствует резидент государства, с которым у РФ нет действующего СИДН? Сквозной подход позволяет игнорировать всех «посредников» (независимо от их количества) между налоговым агентом (российской организацией, выплачивающей доход) и лицом, имеющим ФПД. Такой режим применим даже в случае, когда в цепочке компаний, через которые осуществляется выплата дохода конечному бенефициару, присутствует организация, постоянным местонахождением которой является государство, с которым у РФ отсутствует СИДН 5 . В случае наличия двух и более лиц, имеющих ФПД, являющихся резидентами разных государств, российская организация, выплачивающая такой доход и выполняющая функцию налогового агента в его отношении, вправе также применять

иностранного лица, не имеющего фактического права на их получение. Рекомендуется направлять этот документ в сроки, установленные НК РФ для представ-

๓ ления налоговыми агентами информации о суммах выплаченных иностранным

이 организациям доходов и удержанных налогов. То есть подать сообщение нужно не позднее 28 календарных дней со дня окончания отчетного (налогового) периода, в котором выплачен доход (п. 3 ст. 289, п. 4 ст. 310 НК РФ).

2 При этом под «выплачиваемым доходом», по мнению Минфина РФ, понимается доход от источников в РФ, выплачиваемый иностранному лицу, которое может быть как физическим, так и юридическим лицом, в том числе контролиру-

202 емой иностранной компанией (см.: Письмо Минфина РФ от 21.01.2015 № 03-0805/69517).

${ }^{3}$ При выплате дохода иностранному получателю, ФПД на который обладает российское физическое лицо, с суммы такой выплаты российский налоговый агент обязан удержать надлежащую сумму НДФЛ по общей ставке 13 \% (п. 4 ст. 226 НК РФ).

${ }^{4} \mathrm{~B}$ доктринальных источниках различие в режимах налогообложения пассивных доходов объясняется тем, что «дивиденды всегда (уплачиваются) из чистой прибыли после удержания налога на прибыль организаций, а роялти и проценты учитываются в расходах (доходах), изменяющих налоговую базу по налогу» (Б$a-$ лакина 3. В. Принцип сквозного налогообложения при применении концепции бенефициарного собственника дохода // Актуальные проблемы российского права. 2016. № 11 (72). С. 89).

${ }^{5}$ Письмо Минфина РФ от 19 мая 2015 г. № 03-08-05/28839. 


\section{Финансовое право. Налоговое право}

соответствующие СИДН с теми государствами, резидентами которых являются упомянутые лица, имеющие ФПД6.

Институт сквозного подхода в контексте ФПД продолжает развиваться. По прошествии четырех лет с момента имплементации сквозного подхода в законодательстве о налогах и сборах законодателем была осуществлена его новация ${ }^{7}$. Если прежде п. 1.1 ст. 312 НК РФ ограничивал право иностранного лица - получателя дохода от источника в РФ воспользоваться сквозным подходом исключительно получением дивидендов, то теперь такое право распространено на все виды пассивных доходов.

Был введен упрощенный порядок использования сквозного подхода для: 1) физических лиц; 2) государственных суверенных фондов; 3) организаций, количество торгующихся на бирже акций которых превышает $25 \%$ их уставного капитала, и 4) организаций, если в них прямо участвует российское или иностранное государство, участвующее в применимом СИДН, и доля такого участия составляет не менее 50 \%. Для этого перечисленные лица должны, во-первых, иметь ФПД и, во-вторых, предоставить российскому налоговому агенту письменное подтверждение наличия ФПД и дополнительные документы, удостоверяющие выполнение условий п. 1.5 ст. 312 НК РФ.

При выплате дивидендов был установлен специальный порядок использования сквозного подхода (п. 1.1-1.4 ст. 312 НК РФ). Получив дивиденды от российского источника, иностранная организация может добровольно признать отсутствие ФПД. Тогда возможность применить льготные положения СИДН не утрачивается, но «переходит» к иному лицу, при условии его прялого участия в указанной иностранной организации, а также - прялого и (или) косвенного участия в российской организации, выплатившей дивиденды. Такое «последующее» лицо должно признать свое ФПД на дивиденды в той части, которая соответствует его доле участия в российской организации, выплатившей дивиденды. В противном случае право «претендовать» на льготное налогообложение возникает у следующего лица в соответствующей последовательности участия компаний. И такая «цепочка» может тянуться вплоть до конечного бенефициара, независимо от числа компаний - «промежуточных звеньев», которые не признаются лицами, имеющими ФПД․ Рассмотрим пример.

Допустим, кипрская компания «Альфа» имеет 100 \% прямого участия в российском ОАО «Дельта». В свою очередь, $100 \%$ уставного капитала «Альфы» напрямую владеет французская компания «Бета», которая косвенно - через «Альфу» - участвует в ОАО «Дельта». Если «Альфа», будучи прямым получателем дивидендов, признает отсутствие у себя статуса ФПД, то бенефициарным собственником следует признать именно «Бету». В этом случае при налого-

${ }^{6}$ Письмо Минфина РФ от 24 апреля 2015 г. № 03-08-05/23613.

${ }^{7} \mathrm{O}$ внесении изменений в части первую и вторую Налогового кодекса Российской Федерации и отдельные законодательные акты Российской Федерации о налогах и сборах : федер. закон от 27 ноября 2018 г. № 424-ФЗ // Собр. законодательства Рос. Федерации. 2018. № 49 (ч. 1). Ст. 7496.

${ }^{8}$ См., в частности: Письмо Минфина России от 14 июня 2016 г. № 03-08$05 / 34379$. 


\section{Вестник ВГУ. Серия: Право}

обложении дивидендов применяется Конвенция между Правительствами РФ и Французской Республики от 26 ноября 1996 г. «Об избежании двойного налогообложения и предотвращении уклонения от налогов и нарушения налогового законодательства в отношении налогов на доходы и имущество» ${ }^{9}$. Далее предположим, что в уставном капитале компании «Бета» 100 \% участия принадлежит нидерландской компании «Гамма», которая косвенно - через «Бету» и «Альфу» участвует в уставном капитале «Дельты». Тогда, при условии признания «Бетой» отсутствия ФПД, статус бенефициарного собственника дивидендов переходит к компании «Гамма», а налогообложение выплаченных дивидендов осуществляется с учетом положений Соглашения между Правительствами РФ и Королевства Нидерландов от 16 декабря 1996 г. «Об избежании двойного налогообложения и предотвращении уклонения от налогообложения в отношении налогов на доходы и имущество» ${ }^{10}$.

Как видим, признание права на доходы в виде дивидендов переходит по «цепочке» взаимно владеющих друг другом компаний, что и означает сущность принципа сквозного подхода в контексте ФПД.

Концепт ФПД применяется как ко всему доходу в целом, так и $\kappa$ его части. Очевидно, что если компания-посредник перечисляет конечному бенефициару лишь часть дохода, а другую оставляет себе (например, в виде платы за оказанные услуги), то такая часть признается собственностью компании-посредника, и к ней применяются налоговые льготы, предусмотренные СИДН между РФ и государством - местом резидентства посредника. «В противном случае, - верно замечает Б. Я. Брук, - сложно избежать двойного налогообложения, поскольку государство места нахождения промежуточной компании с большой долей вероятности признает данный доход доходом именно промежуточной компании и не признает правомерность отказа РФ применять в его отношении предусмотренный СИДН льготный налоговый режим» ${ }^{11}$.

Пусть кипрская компания «Альфа» имеет 100 \% прямого участия в российском ОАО «Дельта», а фрранцузская компания «Бета» владеет 85 \% уставного капитала «Альфы». Тогда косвенное участие «Беты» в российской компании «Дельта", источнике дивидендов, согласно п. 3 ст. 105.2 НК РФ составит 85 \% $([100 \% \times 85 \%]: 100 \%=85 \%)$. Если «Альфа» выплачивает эту часть дивидендов «Бете», оставляя себе 25 \% дохода, то именно к доле, равной 85 \%, должны применяться льготные положения СИДН между Правительствами РФ и Француз-

204 ской Республики. Что касается оставшейся суммы (25 \%), то она признается доходом кипрской компании «Альфа», соответственно, к нему должны применяться «льготные» положения Соглашения между Правительствами РФ и Республики Кипр от 5 декабря 1998 г. «Об избежании двойного налогообложения в отношении налогов на доходы и капитал» ${ }^{12}$.

Как и в случае с иными доходами, порядок налогообложения дивидендов у российского налогового агента (источника выплаты) определяется резидентством лица, имеющего ФПД.

${ }^{9}$ Бюллетень международных договоров. 1999. № 7.

10 Там же. № 1.

11 Брук Б. Я. Перспективы кодификации концепции бенефициарного собственника в российском налоговом законодательстве // Закон. 2014. № 8. С. 56.

12 Бюллетень международных договоров. 1999. № 12. 


\section{Финансовое право. Налоговое право}

1. Если конечный бенефициар - резидент третьего государства, у которого нет СИДН с РФ, то удержание налога у источника осуществляется по общим правилам налогообложения дивидендов, т. е. по ставке $15 \%$ (подп. 3 п. 3 ст. 284 НК РФ) без предоставления договорных льгот и преференций.

2. Если конечный бенефициар - резидент государства, с которыли у $P Ф$ илеется СИДН, то при выплате дивидендов применяются договорные льготы и преференции, предусмотренные указанным СИДН.

3. Если конечный бенефициар - резидент $P \Phi$, то российской организацией, выплачивающей доход, не удерживается налог с иностранного лица, не имеющего ФПД на выплачиваемые доходы (их часть), однако она будет выступать налоговым агентом в отношении дохода, получаемого российским резидентом, признанным ФПД ${ }^{13}$. Удержание налога осуществляется по следующим ставкам:

- по ставке 0 \% для российских организаций, при выполнении следующих условий:

1) доля косвенного участия ФПД в уставном капитале российского источника выплаты дивидендов составляет не менее 50 \%;

2) сумма дивидендов, фрактическое право на которые имеет налоговый резидент РФ, составляет не менее 50 \% от общей суммы распределяемых дивидендов;

- по ставке 13 \% для фризических лиц, а также для российских организаций, не имеющих право на применение «нулевой» ставки.

Иностранный получатель дохода должен документально подтвердить свое право на получение налоговых льгот по СИДН ${ }^{14}$. Для этого он обязан предоставить российскому налоговому агенту:

1) документальное подтверждение постоянного местонахождения в государстве, с которым РФ имеет СИДН, заверенное компетентным органом государства-участника, а также его перевод на русский язык;

2) документальное подтверждение ФПД на полученные доходы;

3) документальное подтверждение признания иностранным получателем дохода отсутствия ФПД (в случае «перехода» такого права к третьему лицу);

4) информацию об иностранной организации, признаваемой лицом, имеющим ФПД, которая, в частности, включает: во-первых, указание его доли и документальное подтверждение порядка прямого участия в этой иностранной организации; во-вторых, документальное подтверждение косвенного участия в российской организации - источнике выплаты дивидендов; в-третьих, документальное подтверждение государства налогового резидентства лица.

Законодатель не установил формальных требований к составу и содержанию документов, подтверждающих статус лица, имеющего ФПД. По мнению Минфина РФ, отсутствие упоминания о конкретных документах,

${ }^{13}$ См.: Письмо Минфина России от 16 августа 2016 г. № 03-08-05/47852.

${ }^{14} \mathrm{~B}$ связи с новой редакцией п. 1 ст. 312 НК РФ у иностранных организаций появилось облзательство предоставлять налоговым агентам соответствующие подтверждения, иначе в применении льгот по СИДН им будет отказано. 


\section{Вестник ВГУ. Серия: Право}

необходимых для определения лица, имеющего ФПД, свидетельствует о том, что законодатель не ограничивает налоговых агентов каким-либо перечнем, отдавая предпочтение содержательной части полученной налоговым агентом информации ${ }^{15}$. Здесь проявляется квалифииированное молчание закона - прием юридической техники, когда законодатель сознательно отказывается от нормативной регламентации вопроса либо регламентирует его в самом общем виде, делегируя дальнейшее урегулирование на уровень правоприменения. В данном случае законодатель не говорит «нет», «запрещено», «недопустимо», но признает, что на уровне статутного права исчерпывающая регламентация данного вопроса нецелесообразна.

Таким образом, перечень, форма, содержание и порядок получения документов, подтверждающих (опровергающих) фрактическое право иностранных организаций на выплачиваемые доходы, определяются самостоятельно российской организацией, выплачивающей доход, по ее дискретнолу услотрению, с учетом конкретных условий предпринимательской деятельности и сложившихся взаимоотношений с иностранными партнерами ${ }^{16}$.

Согласно разъяснениям Минфина $Р \Phi^{17}$, при определении лица, имеющего ФПД, могут приниматься во внимание следующие документы (информация):

1) документы (информация), подтверждающие (опровергающие) наличие у получателя дохода права услотрения в отношении распоряжения и пользования полученным доходом, в том числе:

- документы, подтверждающие (опровергающие) наличие договорных или иных юридических обязательств перед третьими лицами (местом резидентства или регистрации которых является государство (территория), с которым РФ не заключен СИДН), ограничивающих права получателя ๓ дохода при использовании полученных доходов в целях извлечения выго이 ды от альтернативного использования;

- документы, подтверждающие (опровергающие) предопределенность последующей передачи получателем дохода денежных средств третьим лицам (местом резидентства или регистрации которых является государство (территория), с которым РФ не заключен СИДН);

2) документы (информация), подтверждающие возникновение у по-

206 лучателя дохода, местом регистрации или резидентства которого является государство (территория), с которым РФ заключен СИДН, объекта налогообложения, налоговых обязательств, подлежащих уплате, наличие которых подтверждает отсутствие экономии на налоге у источника в РФ при последующей передаче полученных денежных средств третьим лицам (местом резидентства или регистрации которых является государство (территория), с которым РФ не заключен СИДН);

${ }^{15}$ Письмо Минфина РФ от 3 июля 2019 г. № 03-08-05/41842.

${ }^{16} \mathrm{~B}$ этом контексте рекомендуется прибегать наряду с другими документами к заверительным письмам и к фбинансовой отчетности, составленной по стандартам МСФО и заверенной аудиторской компанией.

${ }^{17}$ Письмо Минфина РФ от 27 декабря 2018 г. № 03-08-05/95476. 


\section{Финансовое право. Налоговое право}

3) документы (информация), подтверждающие осуществление получателем дохода в государстве (территории), местом регистрации или резидентства которого является государство (территория), с которым РФ заключен СИДН, фрактической предпринимательской деятельности.

Обратим внимание, что какого-либо запроса от налогового агента на представление указанной информации (документов) не требуется. Однако целесообразно включать в трансграничные контракты оговорку об обязательстве иностранного контрагента предоставлять ex ante документы (информацию), раскрывающие его статус в отношении каждого выплаченного дохода.

Установление наличия или отсутствия у лица ФПД во многом опирается на получение от иностранных юрисдикций дополнительной информации о движении денежных средств между компаниями группы, а также отчетности компаний. В качестве доказательств, подтверждающих, что получатель доходов не был реальным бенефициаром полученного дохода, налоговыми органами и судами признаются также коммерческие базы данных, открытые реестры иностранных компаний, информация из общедоступных источников ${ }^{18}$.

Благодаря тому, что после новелл 2018 г. ст. 312 НК РФ сквозной подход в контексте ФПД более не ограничен дивидендами, но распространяется на все виды трансграничных доходов, облагаемых у источника в РФ, в российской доктрине актуализировался вопрос, применим ли сквозной подход в ситуации, когда при перечислении дохода от первоначального его получателя к лицу, имеющему ФПД, вид дохода изменяется? Полагаем, такой давно обсуждаемый в различных юрисдикциях вопрос свидетельствует о непонимании причин и значения разделения понятия «доход» на конкретные его виды.

Каждый вид дохода: дивиденды, проценты по заемным средствам, роялти, выручка от продаж, оказания работ или предоставления услуг, вознаграждение за труд и т. д., - обладает индивидуальной природой и характеристиками, что вызвало обособление по этим характеристикам каждого вида доходов в экономике и в праве. Вначале необходимо доказать неправомерность выделения отдельных видов доходов, существующего столетия в экономической науке и закрепленного в национальном налоговом законодательстве различных правопорядков мира, в положениях СИДН и МК ОЭСР, доказать отсутствие какого-либо значимого экономического различия между видами доходов и существованием одной неразличимой категории «доход». И только после этого можно ставить вопрос о «преемственности», к примеру, роялти, полученных через цепочку посредников иностранным лицом, имеющим ФПД, к дивидендам, выплаченным на территории РФ другому иностранному лицу - первому звену в цепочке посредников ${ }^{19}$.

${ }^{18}$ Письмо Минфина РФ от 2 фревраля 2015 г. № 03-08-05/3841.

19 Придерживаясь той же логики, дивиденды акционерам и оплату труда работников можно ассоциировать с платежами, полученными за поставленную продукцию акционерным обществом от его контрагентов. На таком примере ре- 


\section{Вестник ВГУ. Серия: Право}

В основе поставленного вопроса лежит идея некоего абстрактного «дохода», сохраняющегося для целей СИДН неизменным при передаче от лица к лицу вне зависимости от основания выплаты суммы в каждом конкретном случае. Причем этому неизменному и не зависящему от основания абстрактному «доходу» предлагается придать юридическое значение. Полагаем, идея такого абстрактного и бесформенного «дохода» есть одна из разновидностей обыкновенного логического заблуждения, игнорирующего законы реальности, породившие выделение экономикой самостоятельных видов дохода и придания им правового значения. Такое игнорирование может способствовать двойному неналогообложению или снижению налогового бремени вопреки намерению государств, заключивших СИДН, противодействие чему является одной из целей СИДН, закрепленных в 2014 г. в преамбуле и в Комментарии к ст. 1 МК ОЭСР, а также в преамбуле для СИДН, изложенной в Multilateral Convention to Implement Tax Treaty Related Measures to Prevent BEPS, подписанной более чем восемью десятками государств.

Но ряд спорных вопросов применения сквозного подхода в контексте ФПД, имеющих реальное основание, действительно «остались за рамками» новелл 2018 г.

Например, остро стоит вопрос о распределении бремени доказывания. Так, если в 2015 г. в деле ЗАО «Вотек Мобайл» ${ }^{20}$ суды встали на сторону налогоплательщика и налогового агента, исходя из обязанности налогового органа обосновать и подтвердить фактически заявленные требования, то подход, изложенный в письме ФНС России от 28 апреля 2018 г. № CA-4-9/8285@, перераспределяет бремя доказывания не в пользу налогоплательщиков и налоговых агентов. Именно они, по мнению налогового органа, должны обосновывать необходимость совершения сделок (операций) в определенной форме, вовлечение иностранных компаний в m структуру бизнеса и сделок (операций), а также предоставлять доказа으 тельства разумности сделанного выбора и обоснованности предпринимательского риска.

В свете этого кажется излишне оптимистичным мнение, что новеллы 2018 г., по замыслу российского законодателя, создают «оспоримую презумпцию наличия ФПД, а бремя доказывания обратного возлагается

208 на налоговый орган» ${ }^{21}$. И логика, прослеживающаяся, например, в решении по делу ООО «Русджам Стеклотара Холдинг» ${ }^{22}$, лишь укрепляет нас в этом мнении.

Или другой вопрос, допускается ли сквозной подход, если лицо, имеющее ФПД, является резидентом государства, в СИДН с которым для применения льготных ставок у источника в отношении дивидендов предусмо-

льефнее проявляется ошибочность мысли о «правопреемстве» доходов и подобного толкования look-through approach.

20 Постановление Девятнадцатого ААС от 5 июня 2015 г. по делу № A14$13723 / 2013$.

${ }^{21}$ Кириллов А. В., Васильев Н. А. Применение сквозного подхода при трансграничном налогообложении // Налоговед. 2019. № 8. С. 46.

${ }^{22}$ Решение АС г. Москвы от 10 апреля 2019 г. по делу № A40-8065/18-115-371. 


\section{Финансовое право. Налоговое право}

трено требование прямого участия в уставном капитале? В данном случае позиция российских фискальных органов однозначна: сквозной подход в такой ситуации не применим ${ }^{23}$.

Этому можно было бы противопоставить логику, положенную в основание устойчивой правовой позиции судов, отраженной, например, в делах ООО «ЮИИ Сибирь» ${ }^{24}$ АО «СУЭК Кузбасс» ${ }^{25}$, ОА «Каширский двор Северянин ${ }^{26}$, когда в спорах о недостаточной капитализации, опираясь на подп. «d» п. 15 Комментария к ст. 10 МК ОЭСР, суды приравнивают косвенное участие в уставном капитале к прямому. Но отсутствие практики перенесения правовых позиций по аналогии на иной состав правоотношений не позволяет нам ожидать, что российские суды в спорах о ФПД без труда воспримут логику, прослеживающуюся в спорах о тонкой капитализации, и опровергнут позицию фискальных органов.

В заключение сделаем вывод, что в настоящее время развитие сквозного налогообложения в контексте ФПД в российском налоговом праве привело к расширению его применения на все виды трансграничных доходов, облагаемых у источника в РФ, но ряд проблем его применения остается не урегулированным, ожидая либо следующего шага законодателей, либо инициативы фискальных органов РФ, либо появления судебной практики по возникшему спору соответствующего характера.

\footnotetext{
${ }^{23}$ Письма Минфина России от 7 декабря 2016 г. № 03-08-05/73316 и ФНС России от 10 июля 2017 г. № СД-4-3/13329@.

${ }^{24}$ Постановление Третьего ААС от 6 мая 2013 г. по делу № А33-7550/2012.

${ }^{25}$ Определение ВС РФ от 6 марта 2018 г. по делу № А27-25564/2015.

${ }^{26}$ Определение ВС РФ от от 5 апреля 2018 г. по делу № A40-176513/2016.
}

Юридический институт Сибирского федерального университета (г. Красноярск)

Демин А. В., доктор юридических наук, доиент, профбессор кафбедры предпринилательского, конкурентного и фонансового права

E-mail:demin2002@mail.ru

Николаев А. В., старший преподаватель кафбедры предпринимательского, конкурентного и фбнансового права

E-mail: nikolaev_aleksei@mail.ru
Law Institute of the Siberian Federal University (Krasnoyarsk)

Demin A. V., Doctor of Legal Sciences, Associate Professor, Professor of the Entrepreneurial, Antitrust and Financial Law Department

E-mail:demin2002@mail.ru

Nikolaev A. V., Senior Lecturer of the

Entrepreneurial, Antitrust and Financial Law Department

E-mail:nikolaev_aleksei@mail.ru 